\title{
Teaching of English in Indian Schools through Grammar Translation Method-Low Performance-A Field Study
}

\author{
Preeti Grover \\ Rayat Bahra Group, Ropar, India \\ Email: preetigrover77@gmail.com
}

Received 5 May 2014; revised 20 June 2014; accepted 10 August 2014

Copyright (C) 2014 by author and OALib.

This work is licensed under the Creative Commons Attribution International License (CC BY). http://creativecommons.org/licenses/by/4.0/

(c) (i) Open Access

\section{Abstract}

Teaching and learning of English language as a second language has become a major concern in the present time for all persons who use English in their daily routine and also for the learner's emotional, intellectual, cognitive and social development. Teaching English as a foreign language refers to teaching English to those students whose first language is not English. So far as teaching of English language in our Indian schools (Govt. Schools) is concerned, it is in a dwindling state. The most popular method of teaching English is Grammar Translation Method. The grammar translation method is not the natural way of learning language. In it English is learnt through the medium of mother-tongue. It leads to the low performance on the part of the learners. This study has been made by actually visiting the randomly selected schools of Punjab (distt. Hoshiarpur) to understand the real situation of teaching and learning of English Language in Indian schools. There are several reasons for undertaking the study of teaching English through Grammar Translation Method and causes of low performance as there has been hardly any worthwhile study at micro level pertaining to the Grammar Translation Method. Therefore, this study will be a useful contribution.

\section{Keywords}

TEFL, Syntax, Communicability, Influence

Subject Areas: Education, Linguistics

\section{Introduction}

English, a language with great reach, heritage and influence, is taught all over the world under different circumstances. English as a foreign language indicates the use of English in a non-English speaking region. Its 
study can either occur in the students home country, as part of the normal school curriculum or otherwise in social milieu. TEFL is the teaching of English as a foreign language and this sort of instruction can take place in any country. Typically, EFL is learned either to pass exams as a necessary part of one's education or for career progression while working for an organization with national and international focuses. Teachers of EFL generally assume that students are literate in their mother tongue. Grammar Translation Method focuses on learning the rules of grammar and their application in translation, vocabulary is learned through direct translation from the native language and is taught in the isolated word lists.

\section{Difficulties in Learning English}

“English” is a term that can refer to various dialects, including British, American and many others. Obviously, those studying has English in order to fit into their new country will learn the variety spoken there. However, for those who do not intend to change countries, the question arises of which sort of English to learn. Even for children studying at home, the choice may be made for them in that private language schools or the state school system may only offer one model. The children studying in India are more likely to learn English with a number of problems such as:

1) The difficulties that learners face in the study of English are a consequence of the degree to which their native language differs from English. Language learners often produce errors of syntax and pronunciation as a result from the influence of their L1, such as mapping its grammatical patterns inappropriately onto the L2, pronouncing certain sounds incorrectly, and confusing items of vocabulary. This is known as L1 transfer or "language interference” These transfer effects are stronger for beginners.

2) English language does not have more individual consonant sounds than most languages. In English 24 consonant sounds have their distinct phonemic sounds. The inter dentals, /t/ and /d/ sounds written with "th" are common in English as (three, thin and thing) are relatively rare in other languages. The distinction between /v/ and /w/ causes problems for learners of English language in Punjab as there is no distinct corresponding sound of the phoneme /w/ in regional language. Similarly vowel sounds in Received Pronunciation has twelve monophthongs (pure or single vowel sounds), eight diphthongs (double sounds) and two tripthongs (triple vowels) [1].

3) The syllable structure causes problems for many learners. English allows for a cluster of up to three consonants before the vowel and four after it.

4) The existence of silent letters in words is also a major problem that the students while learning other language do not face. Why these letters are silent, when do they remain silent are the questions that perplexes the students at all stages of learning.

5) Similarly stressed and unstressed syllables also cause many difficulties. Native speakers frequently replace almost any vowel in an unstressed syllable with an unstressed vowel. In some varieties the syllables an, en, in, on and un are pronounced as homonyms. Only Native speakers can usually distinguished between an able, enable and unable but this is very difficult for inexperienced learners.

6) In Teaching and Learning of English involves the difficulty of regional and cultural styles.

7) Spelling rules and syntax structure are the difficulties in writing English.

All the above mentioned difficulties are the obstacles in Listening, Reading, Speaking and Writing English.

\section{The Grammar Translation Method}

The Grammar Translation Method is not the natural way of learning language. In the Natural Method the students are immersed in language and allowed to formulate their own generalizations. The proponents of this method avoid the use of books in the class. It consists of the series of monologues by the teacher, interspersed with exchange of question and answer between the teacher and the taught. The mother tongue is strictly banished. But In Grammar Translation Method English is learnt through the medium of mother tongue. The child first thinks in his mother tongue and then translates his ideas into English. His mind works like a catalyst in which concoction of different ideas and sounds is taking place. When these ideas come out they lose originality. In this method, while teaching text book, the teacher translates every word, phrase and sentence of English into the mother tongue of the child. Similarly the students are required to translate sentences from their mother tongue into English language. In the process the child loses his free expression of thought in English. The grammar is taught deductively in our schools i.e.; by oral presentations and with the help of grammar rules. Rules are first mastered and 
then applied in learning language. This over emphasis on rules creates problems for the students.

1) This method encourages word to word translation which altogether is not possible in learning any language. Speaking or any kind of spontaneous creative output is missing in the curriculum. Students often fail to speak or even write a few lines in the target language. There is no scope for original writing. The students totally become dependent on the mother tongue and they carry this habit even to the higher classes. The main reason is that it binds the language into rules of grammar. The student knows only the rules and fails to apply those rules at the time of writing and speaking [2].

Broadly speaking this method has proved a stumbling block in learning English language in real sense. Thus the present study aims to know the problems of the students and teachers and to recommend the derived measures for the future learners of the foreign language and the policy makers.

\section{Review of the Literature}

The analysis of the teaching and learning of English language through Grammar Translation Method has been made by actually visiting the randomly selected schools of District Hoshiarpur through careful observation. Some scholars have also made contribution to the study and analysis of teaching of English language through Grammar translation Method. Sh. Darshan Singh in his dissertation submitted to Punjab University emphasizes on the defective examination system prevailing in our schools needs to be reformed. Sh. S. k. Arora discussed the language teaching pedagogy [3] [4].

\section{Areas of Study and Sources of Data}

This study is based on the data randomly collected from selected Govt. schools of Distt. Hoshiarpur Punjab. The present study has been done randomly in selected primary schools and upper primary schools of Mahilpur Block 1 \& 2 Hoshiarpur Block 1 \& 2 of Distt. Hoshiarpur. Data pertaining to various aspects of the topic under study has been collected from the respective schools with examination records kept in those schools by the head of the institutions.

Table 1 shows class-wise \% of children who can read English. According to this report it is found that only $52.2 \%$ children of VI Std. can read easy sentences but they cannot tell the meanings of these sentences in their regional language. There are $2.9 \%, 2.3 \%$ and $2.1 \%$ respectively of $6^{\text {th }}, 7^{\text {th }}$ and $8^{\text {th }}$ class who cannot read capital Letters. There are $5.2 \%, 4.7 \%$ and $3.8 \%$ respectively of $6^{\text {th }}, 7^{\text {th }}$ and $8^{\text {th }}$ class who can only read capital letters. $11.9 \%$ of $6^{\text {th }}$ class students can read only small letters. $57 \%$ of $7^{\text {th }}$ class can read only easy sentences and $67.45 \%$ of $8^{\text {th }}$ class can read easy sentences. This information is available with ASER an agency which is working on various research projects in the state [NCERT. National Curriculum Framework].

Table 2 shows class-wise \% of learning level of reading English. After analyzing the above level it is found

Table 1. Class-wise \% of children who can read English.

\begin{tabular}{rccccc}
\hline Std & Cannot read capital letters & Can read capital letters & Can read small letters & Can read simple words & Can read easy sentences \\
\hline Vi & 2.9 & 5.2 & 11.9 & 27.5 & 52.2 \\
Vii & 2.3 & 4.7 & 9.7 & 26.3 & 57.0 \\
Viii & 2.1 & 3.8 & 5.4 & 21.2 & 67.45 \\
\hline
\end{tabular}

Table 2. Class-wise \% of learning level of reading English.

\begin{tabular}{ccccc}
\hline Class & \% capital letters level & \% small letters level & \% word level & \% sentence level \\
\hline $1^{\text {st }}$ & 53.03 & 36.86 & 1.01 & 0 \\
$2^{\text {nd }}$ & 42.63 & 40.1 & 11.16 & 25.92 \\
$3^{\text {rd }}$ & 22.22 & 42.32 & 21.67 & 3.23 \\
$4^{\text {th }}$ & 11.82 & 26.1 & 30.14 & 33.49 \\
$5^{\text {th }}$ & 3.34 & 10.04 & \\
\hline
\end{tabular}


that only $53.03 \%$ children of $1^{\text {st }}$ Std. were at Capital letter level and $36.86 \%$ of $1^{\text {st }}$ Std were at Small letter level $1.01 \%$ were at word level and no one is at the sentence level. It is found that $42.63 \%$ of $2^{\text {nd }}$ Std. were at capital level, $40.1 \%$ were at small letter level $11.16 \%$ students of $2^{\text {nd }}$ Std. were at word level, only $15.22 \%$ of $2^{\text {nd }}$ Std. were at sentence level. Only $4.23 \%, 31.52 \%$ and $33.49 \%$ of $3^{\text {rd }}, 4^{\text {th }}$ and $5^{\text {th }}$ class respectively were at sentence level.

It is also found after personally visiting the schools that teachers neither speak in the target language nor do they give an opportunity to the children to speak. They are only concerned with the syllabus and their only objective is to complete the syllabus. Language is learnt by oral practice and habit formation which is not available in the class room.

\section{Results}

A critical and careful analysis of English language teaching-learning in the country reveals the fact that the learners' achievement is not satisfactory and the factors responsible for this state include non-availability of standard textbooks at reasonable prices, lack of clear cut goals, shortage of well trained and dedicated teachers, lack of suitable teaching-learning technical resources, unrealistic evaluation system and dearth of innovative techniques and methods to handle English should be taught as a language effectively in actual classroom situation. English should be taught as a language effectively in actual class room situation. Through Grammar Translation Method students are taught in the mother tongue with little active use of the target language. Much vocabulary is taught in the form of lists of isolated words. English should be taught as a language not as a subject and the teacher has to be competent in the basic language skills by going through latest materials and attending various training programmes on English language.

The Grammar Translation method stayed in schools until the 1960s, when a complete foreign language pedagogy evaluation was taking place. In the mean time teachers experimented with approaches like the Direct Method, in post war, but much structure to follow.

The Grammar Translation Method set the place for many classrooms for many decades. Because of its extensive history, the Grammar Translation Method provides a backdrop for all the language teaching methods to follow. A possible advantage to the method is its appeal to the logical part of the brain. Students taught using the method are also at an advantage with regard to translation skills, as there is much emphasis placed on direct translation of written work.

Disadvantages to the method include a general lack of communicability in the language, as communicative production is generally ignored.

The deteriorating position of Govt. Schools could be improved so far as teaching of English is concerned. Teachers need to be innovative, resourceful and must have the readiness to impart quality education. The medium of instruction is another issue. Teaching techniques and methodologies needs to be changed. Teacher should restrict the use of mother tongue in the class room. The excessive use of mother-tongue obstructs the free flow of ideas in the target language. The children should be encouraged to speak in the English language. They should be given maximum opportunity to converse and speak among themselves but under controlled supervision so that wrong pronunciation of words should be pointed out if any. So far as possible, real life situations should be created to teach English language. The teacher should take examples from the real world and the situations around him and the class room.

\section{References}

[1] Sethi and Dhamija. An Introduction to English Pronunciation and Spoken English.

[2] Brown, H.D. (2001) An Interactive Approach to Language Pedagogy. 2nd Edition, Pearson Longman, 19.

[3] Singh Sh.D. (1998) Examination Control of the Teaching and Learning Process. A Study of English Examination at the Undergraduate Level, 1-3.

[4] Arora, Sh.S.K. (1980) Dissertation Submitted to PU Chandigarh: “Genesis and Growth of English Grammar”. 81:69. 